\title{
Disseminação das energias renováveis junto às escolas de ensino fundamental e médio da rede pública da grande João Pessoa: sustentabilidade e tecnologia.
}

DOI: 10.37702/2175-957X.COBENGE.2021.3421

Ygor Barbosa Alves - ygor.alves@cear.ufpb.br

Universidade Federal da Paraíba

Rua Itamar Neiva Monteiro 116

58074-000 - João Pessoa - PB

Heitor do Nascimento Andrade - heitor.andrade@cear.ufpb.br

Universidade Federal da Paraíba

Rua Joaquim Borba Filho 555

58053-110 - João Pessoa - PB

Júlia do Nascimento Martins Cabral - julia.cabral@cear.ufpb.br

Universidade Federal da Paraíba

Rua Pres. Nereu Ramos 523

58070-440 - João Pessoa - PB

Emilly Modesto Pereira - modestoemilly71@hotmail.com

Universidade Federal da Paraíba

Rua Tiradentes 550

56280-000 - Araripina - PE

Gabriela Tourinho de Matos Ricardino - gabriela.ricardino@cear.ufpb.br

Universidade Federal da Paraíba

Ramal do mini pólo 2233

68911-160 - Macapá - AP

laryssa Pacheco Teles - iaryssa@cear.ufpb.br

UNIVERSIDADE FEDERAL DA PARAÍBA

Rua jociara telino 85

58053-100 - João Pessoa - PB

Fabiano Cordeiro Cavalcanti - fabianofr@cear.ufpb.br

Universidade Federal da Paraíba

UFPB Universidade Federal da Paraíba sem número 
58051-970 - João Pessoa - PB

Cristiane Kelly Ferreira da Silva - cristianek@cear.ufpb.br

Universidade Federal da Paraíba

Rua dos Milagres 1628

58071-260 - João Pessoa - PB

KELLY CRISTIANE GOMES DA SILVA - GOMES@CEAR.UFPB.BR

UNIVERSIDADE FEDERAL DA PARAÍBA

CIDADE UNIVERSITÁRIA 00

58051-900 - JOAO PESSOA - PB

Resumo: A matriz energética mundial é composta, em sua maioria, por fontes não renováveis de energia e, devido ao uso excessivo destas, são provocados efeitos danosos para o meio ambiente. Tendo isso em vista, a utilização de fontes renováveis de energia como alternativa às fontes convencionais vem sendo intensamente discutida na comunidade científica. No entanto, para que esse debate repercuta junto à sociedade, faz-se necessário que ele também aconteça nos ambientes de formação educacional do nosso país. É neste contexto que foi criado o projeto de extensão intitulado "Disseminação das energias renováveis junto às escolas de ensino fundamental e médio da rede pública da grande João Pessoa: sustentabilidade e tecnologia", cujo o objetivo principal é a disseminação das tecnologias de energias renováveis junto aos alunos das escolas públicas, além de despertar nestes o interesse pelas ciências exatas. O projeto se desenvolveu com a execução de atividades presenciais e em ambiente virtual, assim, este trabalho tem como objetivo apresentar e analisar as ações de extensão desenvolvidas entre os anos de 2019 e 2020. Os resultados obtidos foram satisfatórios tanto no que se refere à produção de materiais didáticos, quanto no que diz respeito ao alcance e engajamento dos alunos como efeito das atividades realizadas.

Palavras-chave: Matriz energética, Sustentabilidade, Educação, Energias renováveis, Engenharia. 


\section{(C) \\ 28 a 30 de SETEMBRO \\ DISSEMINAÇÃO DAS ENERGIAS RENOVÁVEIS JUNTO ÀS ESCOLAS DE ENSINO FUNDAMENTAL E MÉDIO DA REDE PÚBLICA DA GRANDE JOÃO PESSOA: SUSTENTABILIDADE E TECNOLOGIA}

\section{INTRODUÇÃO}

A matriz energética mundial é composta, em sua maioria, por fontes não renováveis, tais como os combustíveis fósseis, representados pelos derivados de petróleo, carvão mineral, gás natural e xisto betuminoso (GOLDEMBERG; LUCON, 2007). Assim, debates sobre a necessidade de substituição desses recursos limitados estão se tornando cada vez mais recorrentes, uma vez que, de acordo com Freitas e Dathein (2013), a utilização dessas fontes gera poluentes - como a emissão de dióxido de carbono na atmosfera - ocasionando um elevado impacto ambiental.

A intensificação do efeito estufa, aquecimento global, chuva ácida, redução da biodiversidade, bem como o esgotamento das fontes são alguns exemplos dos prejuízos trazidos pelo uso de fontes de origem não renovável. Hodiernamente, busca-se pela autossuficiência em geração de energia, aliada a uma diversificação da matriz energética, isto é, a procura por diferentes fontes de energias alternativas e renováveis que supram a demanda interna dos países, no caso de uma escassez de combustíveis fósseis (GUIA, 2019).

Desse modo, têm-se buscado alternativas que aproveitem os recursos naturais de forma sustentável, e é nesse aspecto que as pesquisas no campo das energias renováveis se intensificam a fim de que haja a efetiva mudança no cenário global. Nesse contexto, foi criado o projeto de extensão denominado "Disseminação das energias renováveis junto às escolas de ensino fundamental e médio da rede pública da grande João Pessoa: sustentabilidade e tecnologia" promovido pelo Programa de Bolsas de Extensão (PROBEX) da Universidade Federal da Paraíba (UFPB), em seu terceiro ano de execução.

Diante disso, com o desígnio de disseminar informações sobre as diversas fontes alternativas e de que o debate sobre a importância do uso das energias renováveis tenha um maior impacto social e repercuta em diversos meios, é fundamental que o tema seja inserido no ambiente de formação educacional de crianças e adolescentes. Dessa forma, esse projeto visa, principalmente, suprir essa necessidade, despertando nos alunos uma consciência socioambiental, além de despertar o interesse pela área tecnológica da engenharia de energias renováveis.

Em decorrência da pandemia de Covid-19, infecção respiratória aguda causada pelo novo coronavírus SARS-CoV-2 (BRASIL, 2021), as palestras e as oficinas realizadas nas escolas públicas passaram a ser adaptadas e executadas de forma remota, com a produção de conteúdo para plataformas digitais. Dessa forma, o presente trabalho tem como objetivo apresentar ações realizadas através deste projeto de extensão durante os anos de 2019 e 2020, garantindo a disseminação das energias renováveis nos mais diversos âmbitos.

\section{METODOLOGIA}

No intuito de cumprir o objetivo de disseminar o conhecimento sobre as energias renováveis nas escolas da rede pública da grande João Pessoa, foram realizadas atividades presenciais, como palestras, oficinas e visitas ao laboratório do Centro de 
Energias Alternativas e Renováveis (CEAR) na UFPB, e atividades remotas, tais como palestras on-line, conteúdo no canal do YouTube e publicações semanais pela rede social Instagram. A seguir será detalhado a metodologia das atividades presenciais e remotas utilizadas para alcançar o objetivo.

\subsection{Palestras presenciais}

Foram realizadas palestras presenciais nas escolas, abordando o contexto das energias renováveis no Brasil com o intuito de disseminar o conhecimento, conscientizar e despertar a vocação dos alunos para a engenharia de energias renováveis. Nesse sentido, pode-se destacar os seguintes tópicos abordados nas apresentações:

- Energia e seus conceitos;

- Fontes não-renováveis e seus impactos ambientais;

- Fontes renováveis;

- Matrizes energética e elétrica e a necessidade de diversificação das mesmas;

- Importância das energias renováveis.

\subsection{Visitas aos laboratórios do CEAR}

Foram realizadas visitas aos laboratórios do CEAR para expor aos alunos das escolas participantes os equipamentos utilizados pelos estudantes dos cursos de Engenharia Elétrica e Engenharia de Energias Renováveis em atividades práticas. Os laboratórios visitados foram: Laboratório de Práticas Experimentais em Engenharia, Laboratório de Automação e Controle, Laboratório de Materiais e Química Ambiental, Laboratório de Eletrônica Analógica e Digital, Laboratório de Máquinas Elétricas e Acionamentos, e Laboratório de Síntese e Caracterização de Filmes Finos.

Nas visitas, os professores e os técnicos explicaram as funcionalidades de certos equipamentos, além da realização de demonstrações destes, como, por exemplo, a simulação do funcionamento de faróis de trânsito em um cruzamento e o uso de um tracker, o qual funciona como um rastreador para que os painéis solares sigam a trajetória do sol e potencialize a energia elétrica gerada por ele.

\subsection{Oficinas}

Com o intuito de mostrar o conhecimento na prática, foram realizadas oficinas de montagem dos experimentos abordados a seguir, com os temas de energia eólica, energia solar e energia gerada por biomassa, junto aos alunos das escolas. Estas foram realizadas com o auxílio de cartilhas compostas com os conceitos da aplicação de cada experimento e o passo a passo da sua construção, confeccionadas pelos discentes do projeto. Entre os experimentos, destacam-se o mini aerogerador, o forno solar, o carrinho solar e a composteira PET, detalhados a seguir.

\section{Forno solar}

A energia solar térmica se caracteriza pela conversão direta da radiação solar em calor utilizável, assim, sendo utilizada em diversas aplicações como no aquecimento de água para banho, piscina ou processos industriais (PINHO; GALDINO, 2014). Além disso, também utilizada na aplicação de fornos solares, que assemelham uma estufa de plantas, representando uma das aplicações de maior viabilidade de uso.

Nesse contexto, o forno solar foi escolhido para ser o experimento que aborda de forma prática a energia solar térmica e pode ser visualizado montado na Figura 1. Os materiais utilizados para sua confecção foram papelão, isopor, fita aluminizada, cola quente, fita crepe e uma tampa de vidro. Para utilização, deve ser colocado no sol por certo tempo, dependendo da temperatura que se deseja alcançar. 
Figura 1 - Kit do forno solar montado.

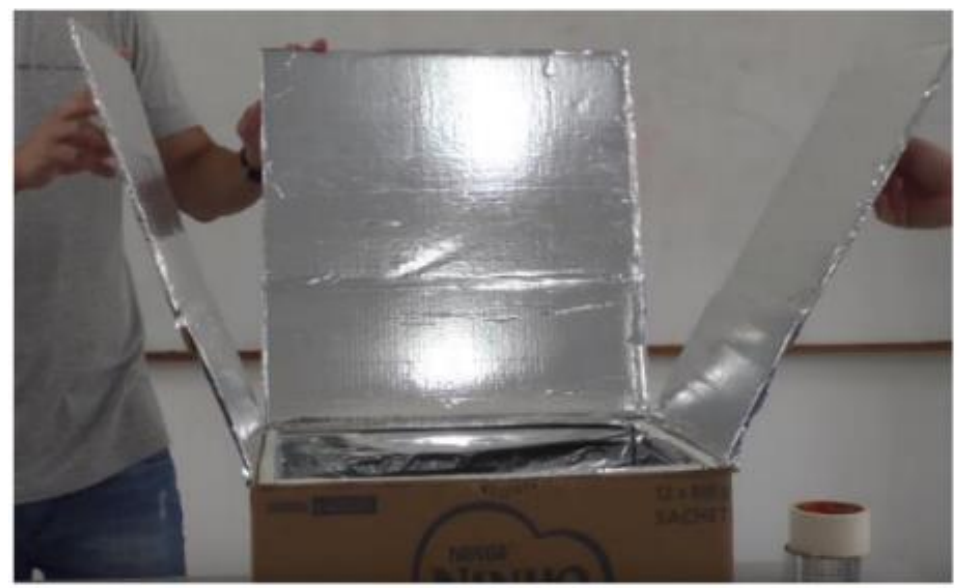

Fonte: Elaborado pelos autores.

\section{Carrinho solar}

Além da energia térmica proveniente da energia solar, a exemplo do forno solar citado anteriormente, a geração de energia elétrica também é possível, através da geração fotovoltaica. $\mathrm{O}$ efeito fotovoltaico consiste na transformação da energia proveniente do sol em eletricidade, através do uso de células fotovoltaicas, compostas nos semicondutores, em que a luz solar incidente sobre essas células provoca a libertação de elétrons, os quais são orientados pelo campo elétrico existente na junção dos semicondutores, gerando uma corrente elétrica proporcional à radiação solar incidente (PINHO; GALDINO, 2014).

Assim, foi escolhido para aplicação junto aos alunos das escolas públicas a confecção de um carrinho de materiais recicláveis movido a energia solar fotovoltaica para mostrar na prática a atuação dessa energia. O carrinho movido a energia solar consiste na base estrutural feita principalmente por espetos de madeira, tampas de garrafas e papelão, com o eixo com a roldana/engrenagem alinhados com o rotor do motor. No momento em que a luz solar incide sobre o carrinho, o motor elétrico é acionado e transfere energia mecânica para as roldanas, movimentando o carrinho. A Figura 2 apresenta o carrinho solar após a efetuação da montagem.

Figura 2 - Kit do carrinho solar montado.

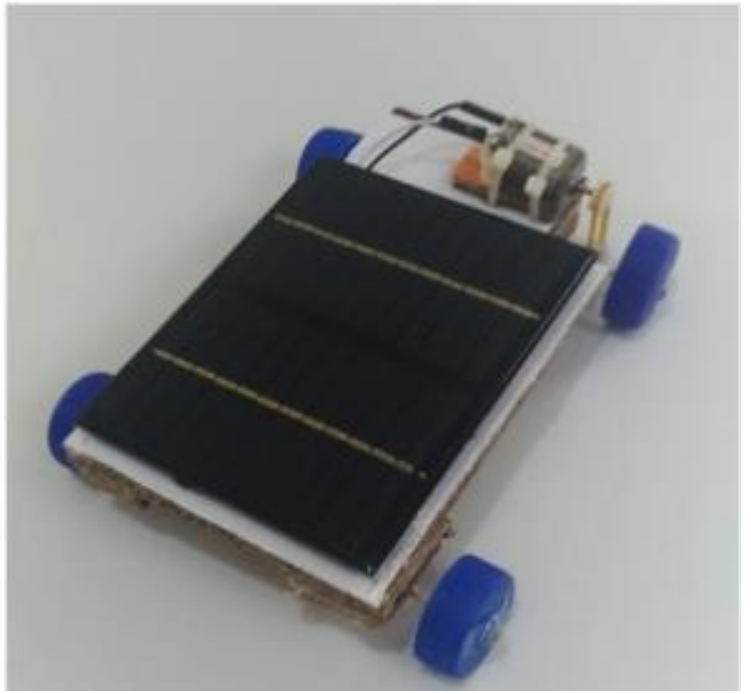

Fonte: Elaborado pelos autores. 


\section{Mini aerogerador}

A energia eólica é um tipo de energia limpa e renovável, obtida através do movimento de massas de ar, as quais colidem com as hélices do gerador eólico, conectadas a geradores, em que a rotação dessas hélices gera energia elétrica (DUTRA, 2008). Com isso, a eficácia para produção dessa energia depende de aspectos como: relevo, velocidade dos ventos, eficiência das instalações e operação e cocais com baixa intensidade de vento e ocorrência de chuvas frequentes se tornam inviáveis para geração, devido à baixa produção, desperdício de energia e ao elevado custo das instalações.

Para aplicar o conhecimento sobre o gerador eólico, foi utilizado um protótipo construído apenas com materiais de fácil disponibilidade e prático de montar, o vento colide com as hélices, sustentadas por uma estrutura de papelão, as quais rotacionam o gerador elétrico, que convertem essa energia mecânica em elétrica, acionando o LED dentro da residência, representando a geração de energia elétrica a partir da energia eólica. As Figuras 3 e 4 apresentam, respectivamente, a estrutura com as hélices e a residência feita de papelão.

Figura 3 - Estrutura com as hélices do aerogerador.

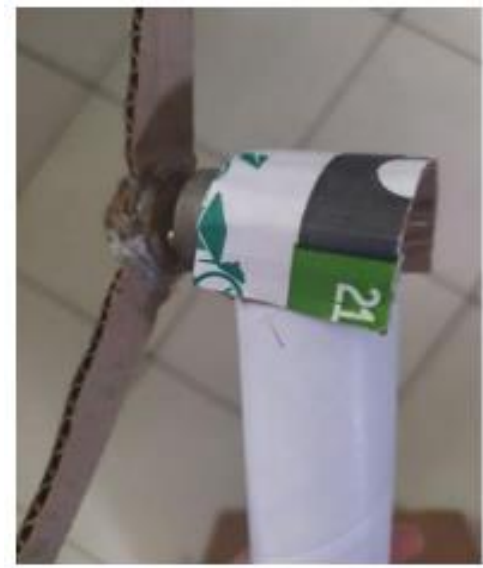

Fonte: Elaborado pelos autores.

Figura 4 - Estrutura da residência feita de papelão.

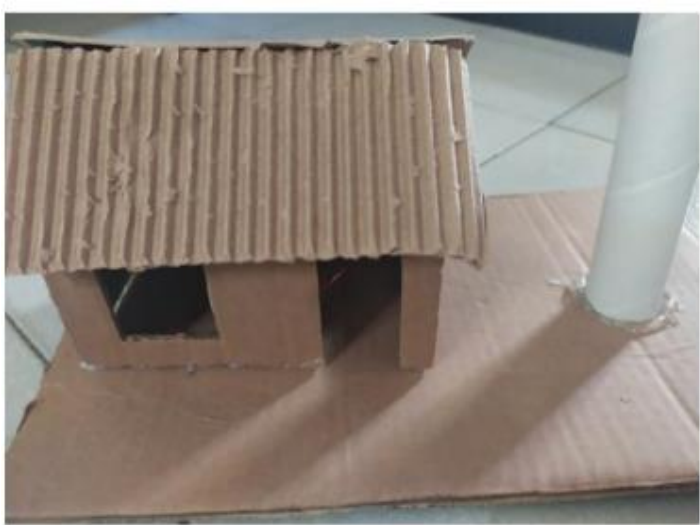

Fonte: Elaborado pelos autores. 


\section{CompostaPET}

Pode-se definir a compostagem como um processo de decomposição aeróbia controlada, que tem como resultado final um produto estável e rico em compostos húmicos, cuja utilização no solo não oferece riscos ao meio ambiente (VALENTE,2009). Assim, esse processo tem como resultado final um produto que pode ser aplicado ao solo para melhorar suas características e as composteiras são os equipamentos utilizados para realizar o processo. Para confeccionar a composteira, os materiais utilizados foram garrafa PET, rebites, uma pequena parte de um cano PVC de 100mm, cola quente e tecido. Deve-se colocar restos de alimentos na composteira, esperar alguns dias e despejar o líquido produzido no solo escolhido para ser aprimorado, assim, podemos ver, na Figura 5, a compostaPET montada.

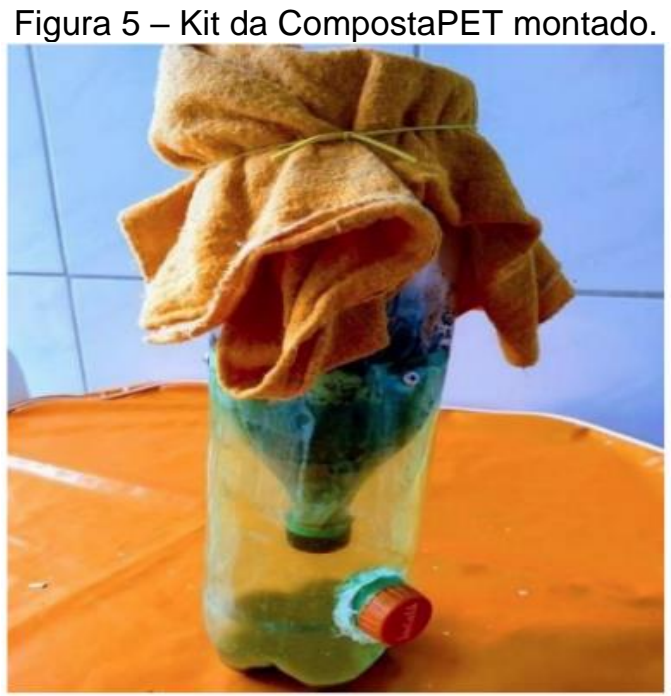

Fonte: Elaborado pelos autores.

\subsection{Atividades realizadas nas plataformas digitais}

Em decorrência da pandemia, novos hábitos e comportamentos estão sendo criados, tanto nas famílias, quanto nas instituições de ensino, que estão revendo uma série de processos, estruturas e metodologias. Em momentos como esse, fica evidente que os problemas exigem soluções criativas e agir de forma rápida para atender melhor os alunos (HODGES, 2020).

Nesse sentido, o uso das ferramentas tecnológicas possibilitou a interação digital dos participantes do projeto com os alunos e pessoas em geral, além de que favorece o processo de ensino e aprendizagem de forma mais eficaz e autônoma (CORDEIRO, 2020).

Os meios de comunicação são variados e dependem do seu público-alvo que, no caso, além de alunos do ensino fundamental e médio, também foi alcançado universitários e usuários da rede em geral. Para isso foi criado um canal no YouTube (Probex Renováveis), mostrado na Figura 6, e um perfil no Instagram (@renovaveis.probex), como consta na Figura 7.

A partir disso, o início das atividades on-line se deu por meio de palestras virtuais assíncronas com objetivo de disseminar conhecimento sobre as principais formas de energias renováveis, seus aspectos ambientais e econômicos. Dentre os principais temas abordados nos vídeos, podem se destacar o conceito, a história, os exemplos, as perspectivas para o futuro e o cenário atual das fontes renováveis de energia no Brasil e no estado da Paraíba. 
O material produzido, além de ter sido postado em séries de vídeos no YouTube, foi enviado para as escolas parceiras aprimorando o contato com os alunos. Dessa forma, os estudantes de ensino fundamental e médio tiveram acesso ao conteúdo proposto pelo projeto. Alinhado a isso, o perfil no Instagram auxiliou na divulgação das palestras, de informações gerais e curiosidades acerca das Energias Renováveis.

Figura 6 - Canal na plataforma YouTube.

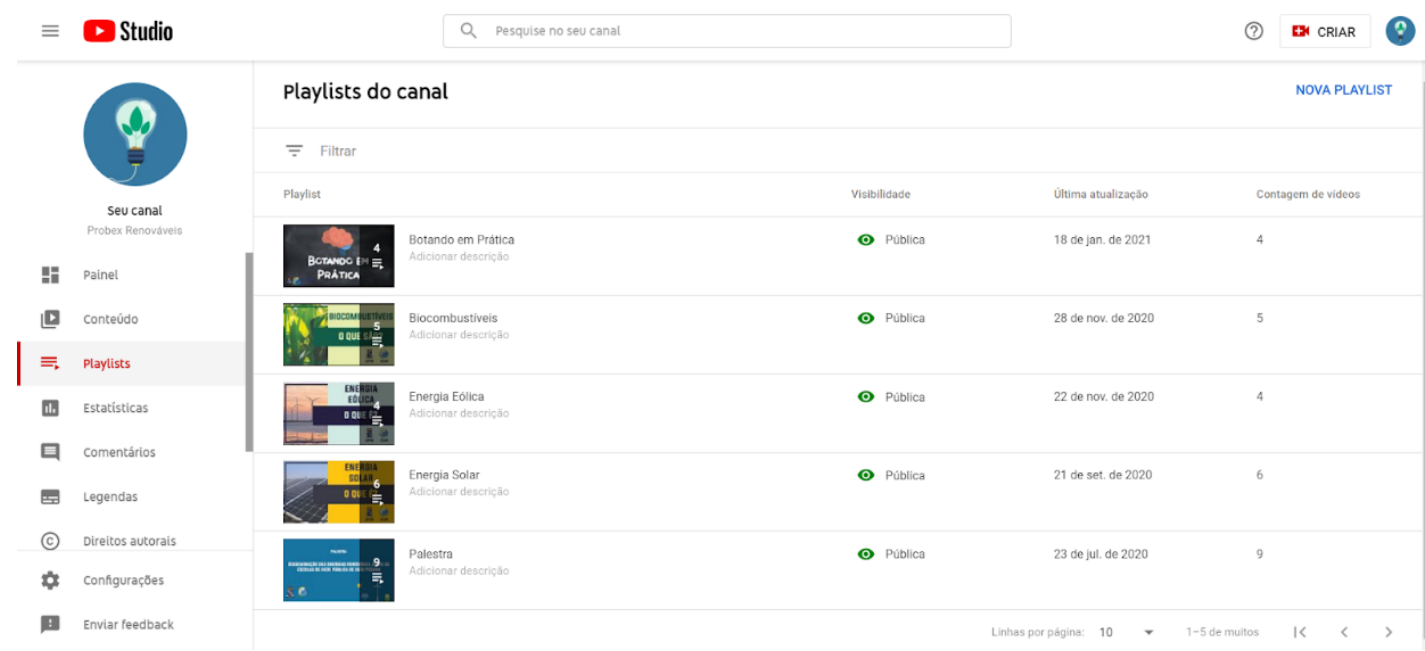

Fonte: Retirada do YouTube.

O conteúdo do Instagram foi postado semanalmente e seguindo uma sequência de 3 publicações por assunto de acordo com o que era publicado no YouTube. Sendo que, a produção das postagens e materiais didáticos no geral passavam por revisões dos professores do projeto, buscando um fácil entendimento pelos alunos da rede de ensino fundamental e médio.

Figura 7 - Perfil na rede social Instagram.

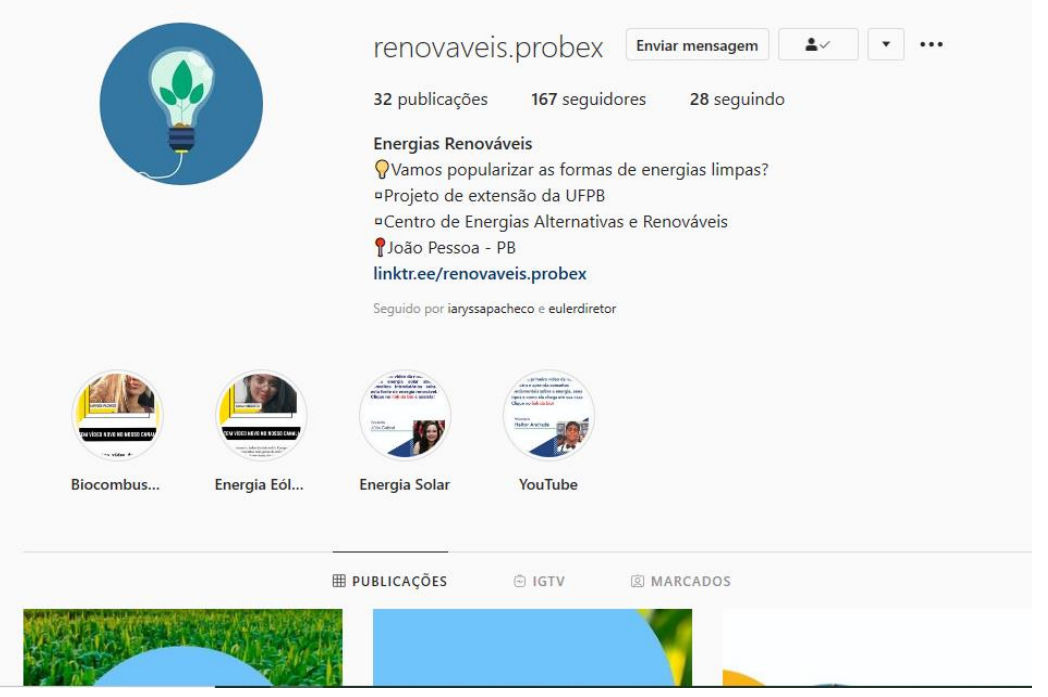

Fonte: Retirada do Instagram. 


\subsection{Ferramentas utilizadas nas atividades remotas}

Para a preparação do conteúdo foi elaborado um roteiro como base das apresentações, assim, nas palestras, foi utilizado o programa PowerPoint com imagens e tópicos dos conteúdos em questão, a seguir, era extraído um vídeo dessa apresentação para a publicação no YouTube.

Para a construção dos vídeos, utilizou-se softwares, como o ShotCut e OBS Studio, os quais possuem ferramentas de edições, como unir, cortar, retirar ruídos e adicionar planos de fundo musicais. Junto a isso, algumas animações foram produzidas no software Adobe AfterEffects, que foram utilizados, principalmente, no vídeo de componentes do sistema solar fotovoltaico e térmico, dinamizando o assunto para o público.

Em relação às artes do Instagram, foram feitas em programas de design gráfico como CorelDraw e Canvas. Cada conteúdo abordado foi divulgado por meio de três publicações e, por esse motivo, as cores e o design seguiam o assunto que seria apresentado. $\mathrm{Na}$ Figura 8, por exemplo, as publicações sobre biomassa foram feitas na cor verde, pois representava os materiais orgânicos, já para as postagens de curiosidades, foram usadas cores em tons pastéis e tons vibrantes.

Figura 8 - Exemplo das artes publicadas nas redes sociais.

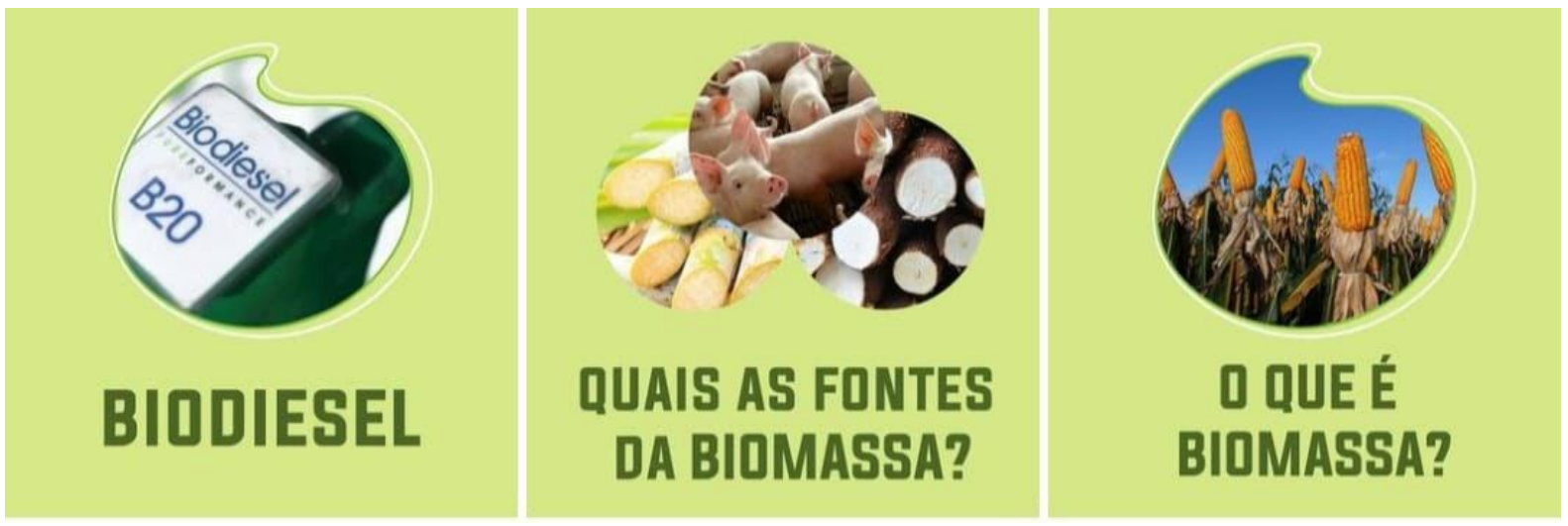

Fonte: Elaborado pelos autores.

\section{$3 \quad$ RESULTADOS E DISCUSSÕES}

\subsection{Alcance de alunos nas atividades presenciais}

Durante o período de execução do projeto antes da pandemia, ocorreram atividades presenciais, citadas anteriormente, como palestras, oficinas e visitas aos laboratórios. Entre as palestras, foram escolhidas 2 escolas públicas estaduais: no mês de maio do ano 2019, - Colégio da Polícia Militar "Estudante Rebeca Cristina Alves Simões" com aproximadamente 65 alunos do $9^{\circ}$ ano do ensino fundamental presentes e, em julho de 2019, ocorreu o evento na ECIT (Escola Cidadã Integral Técnica) Pastor João Pereira Gomes Filho, com uma estimativa de 45 alunos do $1^{\circ}$ ano do ensino médio. A Figura 9 apresenta a realização da palestra no Colégio da Polícia Militar. 
Figura 9 - Palestra realizada no Colégio da Polícia Militar.

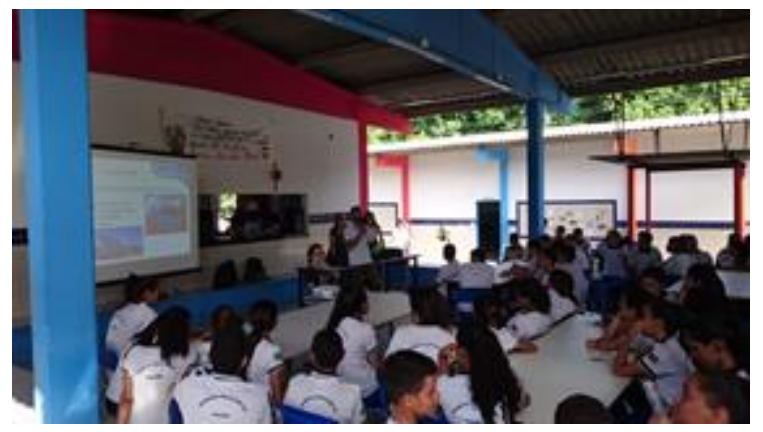

Fonte: Fotografada pelos autores.

Posteriormente, em agosto de 2019, os alunos da primeira escola citada visitaram os laboratórios da UFPB do CEAR e, em outubro de 2019, os alunos da ECIT realizaram a visita. A Figura 10 mostra os professores da UFPB apresentando os laboratórios do CEAR na UFPB aos alunos do Colégio da Polícia Militar.

Figura 10 - Visita aos laboratórios do CEAR na UFPB dos estudantes do Colégio da Polícia Militar.

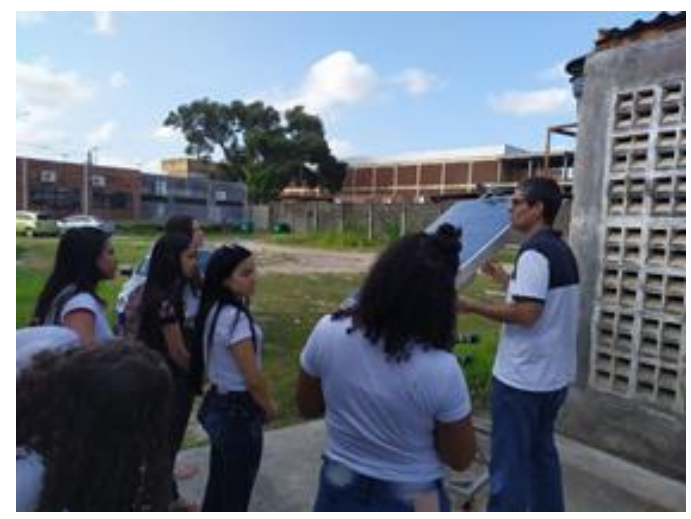

Fonte: Fotografada pelos autores.

Por fim, foi realizada uma oficina no mês de novembro no Colégio da Polícia Militar, em que os alunos construíram um forno solar e um mini aerogerador, em conjunto com os extensionistas. A Figura 11 apresenta a etapa de construção do forno solar com os alunos e após montado.

Figura 11 - Oficina para construção de experimentos no colégio da Polícia Militar.

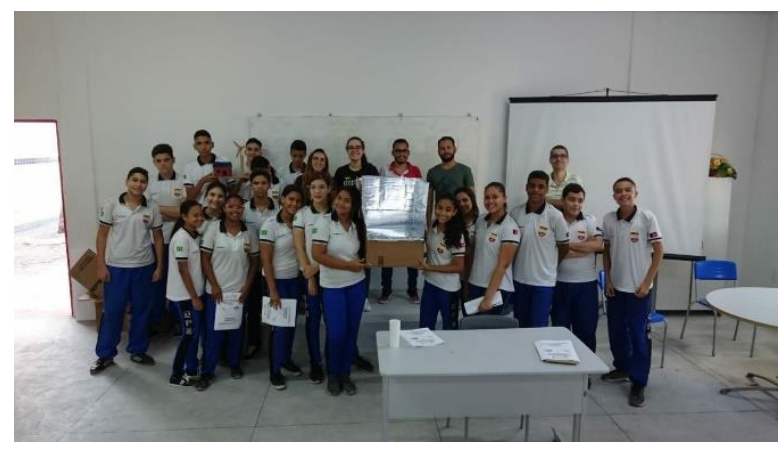

Fonte: Elaborado pelos autores. 


\subsection{Alcance nas plataformas digitais}

Durante o ano em que o projeto foi executado de forma remota - através das plataformas digitais - foram coletados dados acerca do interesse dos alunos sobre os assuntos abordados, tanto no Instagram como no Youtube, além do número de pessoas alcançadas em cada plataforma.

Até o mês de abril de 2021, o canal do YouTube obteve 71 escritos, 1685 visualizações obtidas e em ciclos de 28 dias há um aumento de, em média, 150 visualizações. Dentre os vídeos publicados, os mais assistidos foram, respectivamente, "História da Energia Solar", "Energia Eólica no Brasil e na Paraíba", "História da Energia Eólica" e "O que é energia solar", como consta na Tabela 1. Já no Instagram, o perfil alcançou 167 seguidores, 532 curtidas nas 30 fotos e 251 visualizações nos dois vídeos publicados.

Tabela 1 - Vídeos mais visualizados do canal do YouTube.

\begin{tabular}{c|c|c}
\hline Vídeo & Número de visualizações & Porcentagem (\%) \\
\hline História da energia solar & 402 & 23,9 \\
\hline $\begin{array}{c}\text { Energia eólica no Brasil e na } \\
\text { Paraíba }\end{array}$ & 272 & 16,1 \\
\hline História da energia eólica & 262 & 15,6 \\
\hline O que é energia solar? & 126 & 7,5 \\
\hline
\end{tabular}

Fonte: Dados retirados da plataforma YouTube em abril de 2021.

\section{inferências \\ 3.3 Os meios de disseminação das energias renováveis utilizados e suas}

Através dos números obtidos pelas plataformas digitais, é possível observar que as atividades remotas flexibilizaram a disseminação do conteúdo e que as formas alternativas de geração de energia são um assunto com crescente interesse. A partir disso, observa-se que a divulgação do conteúdo científico pela internet pode servir como um elemento impulsionador de mudanças significativas na sociedade devido ao modo como a comunicação se efetiva (LORDÊLO; PORTO, 2011).

Na forma presencial, apesar de público ter sido reduzido, a realização de palestras e oficinas proporcionaram maior engajamento e interatividade dos alunos, além da resposta imediata sobre o interesse pelas temáticas abordadas. Portanto, conciliar as atividades presenciais com o conteúdo gerado online pode proporcionar a união do impacto do engajamento presencial e da flexibilização do acesso ao conteúdo para os alunos, em que, essa revolução na maneira de educar indica a criação de um ambiente flexível para os alunos, oferecendo uma maior liberdade para conduzir a aprendizagem e o acesso ao material em questão (MARTINS,2018).

\section{CONSIDERAÇÕES FINAIS}

Diante do exposto, é perceptível que esta ação de extensão atingiu não apenas o principal objetivo proposto de disseminar as energias renováveis entre o público jovem das escolas públicas, mas também alcançou outras esferas da sociedade ao adequar o projeto ao âmbito virtual de modo satisfatório. Tal fato é comprovado a partir do número de visualizações nos vídeos postados nas plataformas digitais, e do engajamento de usuários nas redes sociais com perfis tanto acadêmico, quanto profissional e entre outros.

Nesse contexto, é imprescindível ressaltar a importância de inserir assuntos acerca do uso e do desenvolvimento das energias renováveis para a sociedade hodierna, já que se faz necessário diversificar ainda mais a matriz energética nacional e internacional a fim 
de que haja uma efetiva mudança nessa conjuntura global. Para tanto, é fundamental aumentar o número de profissionais na área, e é nesse sentido que se espera que, futuramente, parte desses jovens ingressem com êxito nesse ramo, tornando-se um objetivo a ser alcançado a longo prazo.

Ademais, é possível inferir o quanto a produção do material educacional desta ação de extensão pelos extensionistas em comum com os professores orientadores foi de extrema relevância, uma vez que contribuiu para formação acadêmica, profissional e cidadã de cada um, despertando o interesse pela área tecnológica, já que é através desta que o conhecimento e a aprendizagem se desenvolvem, principalmente, nesse cenário pandêmico atual.

\section{Agradecimentos}

À Universidade Federal da Paraíba, que por meio da Pró-Reitoria de Extensão, possibilitou a realização deste projeto, ao Centro de Energias Alternativas e Renováveis, por disponibilizar os laboratórios para as visitas, aos professores que guiaram os estudantes participantes, e às escolas públicas que abriram suas portas para este projeto.

\section{REFERÊNCIAS}

BRASIL. Ministério da Saúde. O que é a Covid-19? Brasil: Ministério da Saúde. Disponível em: O que é a Covid-19? — Português (Brasil) (www.gov.br). Acesso em: 25 mar. 2021.

CORDEIRO, K. O Impacto da Pandemia na Educação: A Utilização da Tecnologia como Ferramenta de Ensino. 2020. Disponível em:

http://idaam.siteworks.com.br/jspui/handle/prefix/1157. Acesso em: 25 mar. 2021.

DUTRA, Ricardo. Energia eólica: Princípios e tecnologia. Rio de Janeiro: Centro de Referência para Energia Solar e Eólica Sérgio de Salvo Britto, 2008.

FREITAS, G.; DATHEIN, R. As energias renováveis no Brasil: uma avaliação acerca das implicações para o desenvolvimento socioeconômico e ambiental. Rene: Revista Nexos Econômicos, [s. I.], v.7, n.1, p. 71-93, janeiro/junho, 2013.

GOLDEMBERG, J.; LUCON, O. Energias Renováveis: um futuro sustentável. Revista USP, São Paulo, SP, n.72, p. 6-15, dezembro/fevereiro, 2006-2007.

HODGES, Charles et al. Diferenças entre o aprendizado online e o ensino remoto de emergência. Revista da Escola, Professor, Educação e Tecnologia. Tradução de Danilo Aguiar, Dr. Américo N. Amorim e Dra. Lídia Cerqueira. [s. I.], v. 2, p. 1-12, 27 mar. 2020.

LORDÊLO, F.; PORTO, C. A INTERNET COMO FERRAMENTA DE DIVULGAÇÃO CIENTÍFICA SOBRE ENERGIAS RENOVÁVEIS. Uniciências, [s. I.], v.15, n.1, p. 313323, 2011.

MARTINS, T. Evasão Universitária no Ensino à Distância: Análise de fatores influenciadores. Revista Estudos e Pesquisas em Administração, Vol.2, n.2, p. 147163, agosto, 2018. 
PINHO, João Tavares; GALDINO, Marco Antonio. Manual de engenharia para sistemas fotovoltaicos. Rio de Janeiro, v. 1, 2014.

VALENTE, B. S. et al. Fatores que afetam o desenvolvimento da compostagem de resíduos orgânicos. Archivos de zootecnia, Córdoba, v. 58, n. 224, p. 59-85, 2009.

\title{
DISSEMINATION OF RENEWABLE ENERGIES WITH THE FUNDAMENTAL AND MIDDLE SCHOOLS OF THE PUBLIC NETWORK OF GRANDE JOÃO PESSOA: SUSTAINABILITY AND TECHNOLOGY
}

\begin{abstract}
The global energy matrix is mostly composed of non-renewable energy sources and due to the excessive use of those, harmful effects are caused to the environment. With that in mind, the use of renewable energy sources as an alternative to conventional sources has been even more discussed in the scientific community. However, to make this debate reverberate in the society, it is necessary that it also happens in the educational environments of our country. It is in this context that the extension Project entitled "Dissemination of renewable energies among local public elementary and high schools of the great João Pessoa: Sustainability and technology" was developed, with the main goal of disseminating renewable energy technologies among public school students, in addition to arousing their interest in exact sciences. The project was developed by executing activities both in-person and in virtual environments. Therefore, this work aims to present and analyze the extension activities developed between 2019 and 2020. The results achieved were satisfactory both in terms of production of educational material and in terms of reach and engagement of the students as an effect of the performed activities.
\end{abstract}

Keywords: Energetic Matrix, Sustainability, Education, Renewable Energy, Engineering. 